\title{
Ni Corrosion Product Layer During Immersion in a 3.5\% NaCl Solution: Electrochemical and XPS Characterization
}

\author{
B.I. Onyeachu, ${ }^{a}$ E.E. Oguzie,${ }^{b, *}$ I.C. Ukaga, ${ }^{b}$ D.I. Njoku ${ }^{b}$ and X. Peng ${ }^{c}$ \\ ${ }^{a}$ Department of Chemistry, Edo University, Iyamho, Edo State, Nigeria \\ ${ }^{b}$ Electrochemistry and Material Science Research Unit, Department of Chemistry, \\ Federal University of Technology, Owerri, Imo State, Nigeria \\ ${ }^{c}$ State Key Laboratory for Corrosion and Protection, Institute of Metal Research, \\ Chinese Academy of Science, 62 Wencui Road, Shenyang 110016, China
}

Received July 29, 2016; accepted February 06, 2017

\begin{abstract}
Long term wet corrosion resistance of metals depends on the stability of their corrosion product layer. With immersion corrosion tests, such stability can be predicted. EIS and potentiodynamic polarization were complemented with XPS to investigate the characteristics of $\mathrm{Ni}$ corrosion product layer formed after $1 \mathrm{hr}$. and $72 \mathrm{hr}$. immersion in $3.5 \% \mathrm{NaCl}$ solution. Two time constants with decreasing Nyquist semi-circle size and phase angle maxima, based on EIS characterization during the immersion times, indicated the formation of an increasingly porous and less adherent corrosion product layer. The product formation shifted the $\mathrm{Ni}$ corrosion potential more negatively and increased cathodic and anodic current densities, during potentiodynamic polarization. XPS characterization suggested that a rapid nucleation of $\mathrm{NiO}$ could increase $\mathrm{H}_{2} \mathrm{O}$ adsorption, subsequently triggering the formation of different forms of $\mathrm{Ni}(\mathrm{OH})_{2}$ in the corrosion product layer. Consequently, the corrosion resistance of the $\mathrm{Ni}$ coating decreased after $72 \mathrm{hr}$. immersion in $3.5 \% \mathrm{NaCl}$ solution.
\end{abstract}

Keywords: Ni coating, XPS, EIS, NiO, immersion test, corrosion product layer.

\section{Introduction}

The corrosion resistance of metallic materials is a function of the corrosion product layer characteristics formed in the corrosion environment. Surface modification through nano-crystallization of grain size, which has been achieved through various sputtering and deposition techniques, has been reported to greatly improve the corrosion resistance of these metallic materials [1-10]. Nanocrystalline Ni metal and its alloys have gained wide industrial application, especially because of the good corrosion resistance of Ni. The highly reduced grain size facilitates a faster nucleation of $\mathrm{Ni}$ corrosion products (due to the higher density of surface atoms), promotes easier linkage of the corrosion

\footnotetext{
* Corresponding author. E-mail address: emekaoguzie@gmail.com
} 
product nuclei (due to the highly reduced inter-particle spacing), and allows continuous outward supply of $\mathrm{Ni}$ atoms through the abundant grain boundaries to the reaction front for replenishment and participation in the corrosion process. In wet environments, these factors ultimately promote the formation of a more continuous and compact corrosion product layer [6]. Nevertheless, understanding how prolonged exposure affects the stability of the Ni corrosion product layer, in such wet environments, is fundamental towards ascertaining its long term protectiveness. The electrodeposited nanocrystalline Ni coating exhibited higher corrosion resistance than the microcrystalline counterpart in a $3 \% \mathrm{NaCl}$ solution, courtesy of the rapid formation of a fine and compact corrosion product layer composed of $\mathrm{NiO}$ and $\mathrm{Ni}(\mathrm{OH})_{2}$ [6]. The formation of this corrosion product layer resulted in reduced anodic, cathodic and passivation current densities, as well as increased passivation potential range. However, the corrosion product layer characterization focused mainly on a surface probe without due consideration to a depth profiling approach which could provide more detailed information about the distribution of the corrosion products, especially at the corrosion product layer-substrate interface. Recent reports based on electrochemical characterization, however, have shown that the corrosion resistance of the electrodeposited $\mathrm{Ni}$ coating decreased with prolonged exposure in a more aggressive $3.5 \% \mathrm{NaCl}$ containing solution [11]. Therefore, despite establishing the constituents of the $\mathrm{Ni}$ corrosion product layer, characterizing their transformation mechanism over time, is highly imperative. Such characterization could provide clearer insight into the usability span of $\mathrm{Ni}$ coatings, for wet application during deployment.

In the present work, we have employed electrochemical techniques to characterize the corrosion resistance of an electrodeposited Ni coating after $1 \mathrm{hr}$ and $72 \mathrm{hr}$ immersion in a $3.5 \% \mathrm{NaCl}$ solution. Subsequently, we have utilized $\mathrm{X}-$ ray photoelectron spectroscopy (XPS) to perform depth profiling of the corrosion product layer formed by the polarized $\mathrm{Ni}$ coating after the immersion times in a $3.5 \% \mathrm{NaCl}$ solution.

\section{Experimental}

\section{Materials preparation}

The reagents used for all solutions preparation were of analytical (BDH) grade and were used without further purification. All solutions were prepared using distilled water. The $\mathrm{Ni}$ coating was fabricated using direct current electrodeposition, on pure $(99.9 \%) \mathrm{Ni}$ substrate, with the dimensions (12 X $10 \mathrm{X}$ 12) $\mathrm{mm}^{3}$. The substrates were prepared by mechanically abrading to final 800 grit size using $\mathrm{SiC}$ paper, followed by washing with distilled water, cleaning in acetone (with ultrasonic vibration) and drying with a mechanical dryer. The procedure for the $\mathrm{Ni}$ coating electrodeposition has been detailed in our earlier reports $[11,12]$. The as-deposited Ni coating samples were, thereafter, dried in an oven at $105^{\circ} \mathrm{C}$ for $2 \mathrm{hr}$ and kept in an oxygen-free desiccator. 


\section{Electrochemical characterization}

The electrochemical characteristics of the $\mathrm{Ni}$ corrosion product layer were investigated after immersing the Ni coating samples for $1 \mathrm{hr}$ and $72 \mathrm{hr}$ in a $3.5 \%$ $\mathrm{NaCl}$ solution. The $\mathrm{Ni}$ coating was utilized as working electrode in a three electrode system, where a platinum sheet functioned as the counter electrode, and a saturated calomel electrode (SCE), connected through a Luggin capillary, was used as reference electrode. The working electrode was prepared by embedding in a mixture of paraffin and rosin, so that a working area of $100 \mathrm{~mm}^{2}$ was exposed for the corrosion characterization. The employed electrochemical techniques include electrochemical impedance spectroscopy (EIS) and potentiodynamic polarization. The coating samples were first allowed to attain stable open circuit potentials for $30 \mathrm{~min}$ before each experiment. The electrochemical measurements were performed by using a PARSTAT 273A Potentiostat/Galvanostat (Princeton Applied Research) connected to a signal recovery model 5210 lock-in amplifier for EIS acquisition. The EIS measurement was performed by applying a signal amplitude perturbation of 10 $\mathrm{mV}$ in a frequency range of $100 \mathrm{kHz}$ to $0.1 \mathrm{~Hz}$. Potentiodynamic polarization measurement was performed during a $0.166 \mathrm{mV} / \mathrm{s}$ potential scan from -0.25 $\mathrm{V} / \mathrm{OCP}$ to $+0.25 \mathrm{~V} / \mathrm{SCE}$.

\section{Corrosion product characterization}

The chemistry of formation and transformation of the Ni corrosion products after $1 \mathrm{hr}$ and $72 \mathrm{hr}$ exposure with subsequent polarization in a $3.5 \% \mathrm{NaCl}$ solution, was characterized using the XPS-ESCALAB 250 Thermo VG X-ray spectrometer with monochromatic $\mathrm{AlK}_{\alpha}(1486.6 \mathrm{eV})$ radiation source at a pass energy of $1 \mathrm{keV}$ and on a sample area of $2 \mathrm{~mm} \mathrm{X} 2 \mathrm{~mm}$. Sputtering was performed at a rate of $0.04 \mathrm{~nm} / \mathrm{s}$ for 0,10 and $40 \mathrm{sec}$. Subsequent spectra peak deconvolution of the $\mathrm{Ni} 2 \mathrm{p}_{3 / 2}$, and $\mathrm{O} 1 \mathrm{~s}$ peaks was performed with the aid of XPSPEAK4.1 processing software (Chemistry Ltd., CUHK) in the Shirley background after calibrating with the $\mathrm{C} 1 \mathrm{~s}$ peak at $284.6 \mathrm{eV}$.

\section{Results and discussion}

\section{Electrochemical impedance spectroscopy (EIS)}

During the immersion times, the EIS characterization at OCP can provide information concerning the mechanism and rate of charge transfer both at the surface of the Ni coating and through a corrosion product layer formed in the $3.5 \% \mathrm{NaCl}$ solution. The EIS results have been represented in the Nyquist, Bode phase angle and Bode modulus formats, as shown in Fig. 1. In the plot of real impedance against imaginary impedance, the Nyquist plot, after each immersion time, Fig. 1(a), revealed a small semi-circle at high frequency and a large incomplete semi-circle spanning through the intermediate to the low frequency region, with a slight diffusion phenomenon. Such diffusion can be attributed to the movement of reaction species like hydroxide and chloride ions, as well as oxygen, through a very thin layer, such as a corrosion product, formed on the coating surface $[6,13-16]$. The shape of the impedance plot is synonymous with 
the formation of a corrosion product layer experiencing partially localized breakdown [17]. The size of the Nyquist semi-circle correlates with the corrosion resistance of the electrode. From the decrease in the size of the Nyquist plots after $72 \mathrm{hr}$ immersion, it is obvious that the corrosion resistance of the $\mathrm{Ni}$ coating in the $3.5 \% \mathrm{NaCl}$ solution decreased as immersion time increased. The corresponding Bode phase angle plots for the coating are shown in Figure 1(b). After both immersion times, the phase angle plots revealed two impedance loops, which decreased in maxima after $72 \mathrm{hr}$ immersion, at high and low frequency. The phase angle plots indicate that the mechanism of the Ni coating corrosion in the $3.5 \% \mathrm{NaCl}$ solution can be explained using two time constants which correspond to the charge transfer processes occurring at a corrosion product layer $-\mathrm{NaCl}$ interface and at the substrate- $\mathrm{NaCl}$ interface (beneath the corrosion product layer). The reduction in the maximum phase angle, and the noticeable shift of the high frequency loop towards lower frequency after $72 \mathrm{hr}$ immersion, can be attributed to certain localized thinning of the Ni corrosion product layer [18]. In a previous work [11], SEM surface characterization also revealed that the corrosion products, which formed sparsely in the crevices between the large surface grains of a similar Ni coating, were highly prone to attack by chloride ions, leading to localized pitting corrosion after prolonged immersion up to $72 \mathrm{hr}$ in a $3.5 \% \mathrm{NaCl}$ solution.


Figure 1. Nyquist (a), Phase angle (b), and Absolute impedance (c) plots for nickel coating after $1 \mathrm{hr}$ and $72 \mathrm{hr}$ immersion in a $3.5 \% \mathrm{NaCl}$ solution.

Our impedance observation differs markedly from the report of [6] for nanocrystaline $\mathrm{Ni}$ coating in a $3 \% \mathrm{NaCl}$ solution without an immersion time experiment. According to them, the Nyquist diffusion phenomenon was observed at low frequency, and corresponded with a single time constant in the phase angle plot. It, therefore, indicates that concentration and time can seriously 
modify the electrochemical characteristics of the Ni corrosion product layer in aqueous $\mathrm{NaCl}$ solutions.

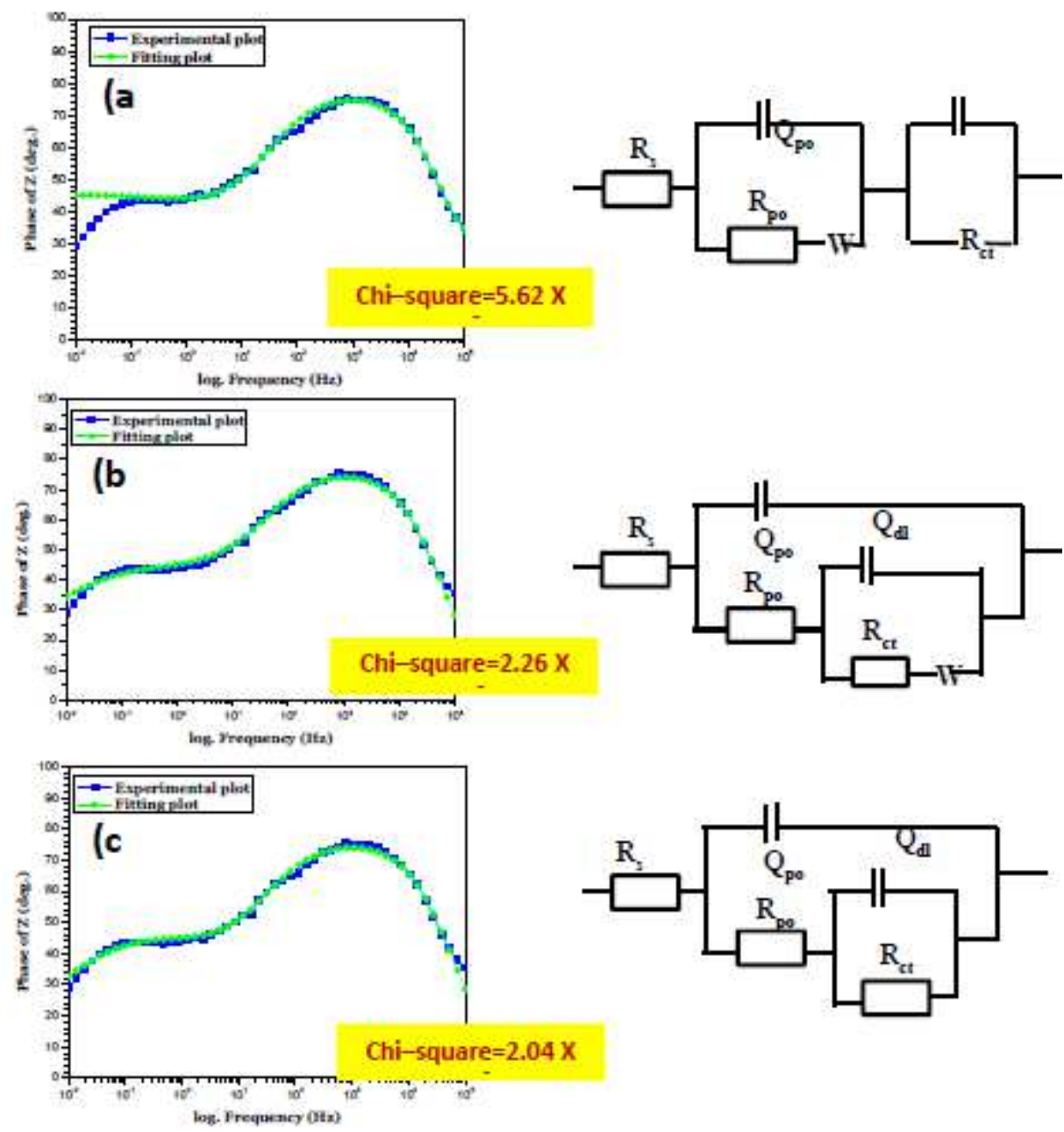

Scheme 1. Equivalent circuit model fittings for nickel coating impedance behaviour after $1 \mathrm{hr}$ and $72 \mathrm{hr}$ immersion in a $3.5 \% \mathrm{NaCl}$ solution.

In order to correlate the impedance result with electrical elements, the ZSimpWin software was deployed to derive an appropriate electric model for the impedance phenomenon. According to the two time constants exhibited in the Phase angle plots, three different models were tested, as shown in Scheme 1(a), 1(b) and 1(c). Consequently, the equivalent circuit model in Scheme 1(c) with the best overlap between experimental and fitting curves (especially at the low frequency regions) and least chi-square value was adapted to model the impedance behavior of the $\mathrm{Ni}$ coating in a $3.5 \% \mathrm{NaCl}$ solution. The values of the resultant electrical elements derived by using the ZSimpWin software are presented in Table 1. In the model, $R_{s}$ is the solution resistance, the elements $Q_{p o}$ and $R_{p o}$ are, respectively, the corrosion product layer capacitance and pore resistance, while $Q_{d l}$ and $R_{c t}$ represent, respectively, the capacitance of charge and resistance to charge transfer at the electric double layer formed beneath the corrosion product layer. 
The $R$ values are measures of the compactness and corrosion resistance of the corrosion product layer, while the $Q$ values depict its dielectric properties. The decrease in $R$ values and increase in $Q$ values, after $72 \mathrm{hr}$ immersion, confirm that the $\mathrm{Ni}$ corrosion product layer became more porous and increased the diffusion of stored charges across its interface (even as the value of $n_{2}=0.5$ further confirms). This is the reason for the decrease in corrosion resistance of the $\mathrm{Ni}$ coating with immersion time in a $3.5 \% \mathrm{NaCl}$ solution.

Table 1. Impedance parameters for Ni coating after $1 \mathrm{hr}$ and $72 \mathrm{hr}$ immersion in a $3.5 \%$ $\mathrm{NaCl}$ solution.

\begin{tabular}{|l|c|c|c|c|c|c|c|}
\hline Immersion time & $\boldsymbol{R}_{s}\left(\boldsymbol{\Omega} \mathbf{c m}^{2}\right)$ & $\boldsymbol{Q}_{p o}\left(\mathbf{F} / \mathbf{c m}^{2}\right)$ & $\boldsymbol{n}_{\boldsymbol{I}}$ & $\boldsymbol{R}_{f}\left(\boldsymbol{\Omega} \mathbf{c m}^{2}\right)$ & $\boldsymbol{Q}_{\text {dl }}\left(\mathbf{F} / \mathbf{c m}^{2}\right)$ & $\boldsymbol{n}_{2}$ & $\boldsymbol{R}_{c t}\left(\boldsymbol{\Omega} \mathbf{c m}^{2}\right)$ \\
\hline $1 \mathrm{hr}$ & 6.14 & $2.72 \times 10^{-6}$ & 0.9 & 6389 & $1.84 \times 10^{-5}$ & 0.5 & $4.56 \times 10^{5}$ \\
\hline $72 \mathrm{hr}$ & 6.37 & $1.01 \times 10^{-5}$ & 0.8 & 6334 & $5.46 \times 10^{-5}$ & 0.5 & $5.79 \times 10^{4}$ \\
\hline
\end{tabular}

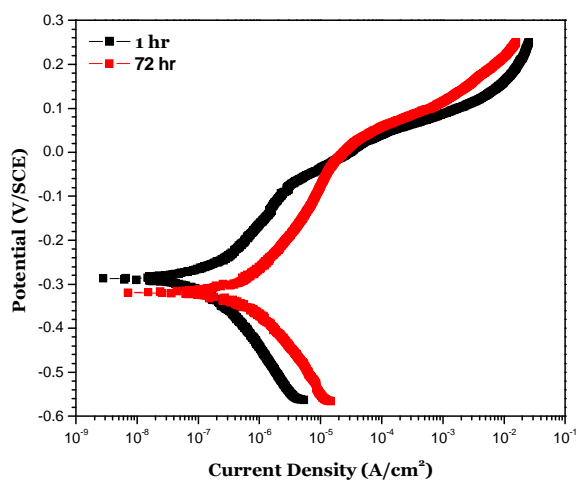

Figure 2. Potentiodynamic polarization plots for nickel coating after $1 \mathrm{hr}$ and $72 \mathrm{hr}$ immersion in a $3.5 \% \mathrm{NaCl}$ solution.

\section{Potentiodynamic polarization}

It is well known that, during a potential scan, the simultaneous anodic and cathodic half-reactions occurring at the metal surface usually lead to the formation of a corrosion product layer, and its characteristics influence the properties of the polarization curve and its derivable parameters. The potentiodynamic polarization plots for the Ni coating after $1 \mathrm{hr}$ and $72 \mathrm{hr}$ immersion in the $3.5 \% \mathrm{NaCl}$ solution are presented in Fig. 2. The derivable polarization parameters, namely, the corrosion potential $\left(E_{c o r r}\right)$ and corrosion current density $\left(j_{c o r r}\right)$ were extrapolated from the intersection of the anodic and cathodic Tafel slopes drawn $\pm 10 \mathrm{mV}$ around the OCP. The values are presented in Table 2. Based on Table 2, the $E_{\text {corr }}$ value became more negative, changing from $-288 \mathrm{mV}$ after $1 \mathrm{hr}$ to $-315 \mathrm{mV}$ after $72 \mathrm{hr}$ immersion in the $3.5 \% \mathrm{NaCl}$ solution. This indicates the increased tendency for dissolution in the solution. The $j_{\text {corr }}$ value, on the other hand, is a measure of the corrosion rate of the coating. Accordingly, there was a higher $j_{\text {corr }}$ value of $0.522 \mu \mathrm{A} / \mathrm{cm}^{2}$ after $72 \mathrm{hr}$ immersion, compared with $0.139 \mu \mathrm{A} / \mathrm{cm}^{2}$ after $1 \mathrm{hr}$, showing that the corrosion product layer, with time, could not impede the rate of electron transfer through its interface. 
Table 2. Polarization parameters for Ni coating after $1 \mathrm{hr}$ and $72 \mathrm{hr}$ immersion in a $3.5 \% \mathrm{NaCl}$ solution.

\begin{tabular}{|c|cccc|}
\hline Immersion time & $\begin{array}{l}\boldsymbol{E}_{\text {corr }}(\mathbf{m V}) \\
(\mathbf{m V} / \mathbf{d e c})\end{array}$ & $\boldsymbol{j}_{\text {corr }}\left(\boldsymbol{\mu} \mathrm{A} / \mathbf{c m}^{2}\right)$ & $\boldsymbol{\beta}_{\boldsymbol{a}}(\mathbf{m V} / \mathbf{d e c})$ & $\boldsymbol{\beta}_{\boldsymbol{c}}$ \\
\hline $1 \mathrm{hr}$. & -288 & 0.139 & 129 & -175 \\
$72 \mathrm{hr}$. & -315 & 0.522 & 167 & -154 \\
\hline
\end{tabular}

Furthermore, Fig. 2 shows that immersion time caused an increase in both the cathodic and anodic current densities. A highly favorable cathodic reaction, which can proceed in such a neutral solution as the $3.5 \% \mathrm{NaCl}$ solution, is the reduction of oxygen and water molecules into hydroxide ions (Equation 1).

Such phenomenon would favor the formation of $\mathrm{Ni}(\mathrm{OH})_{2}$, rather than the more protective $\mathrm{NiO}$. The higher anodic current density reveals an increase in the oxidation rate of $\mathrm{Ni}$ atoms after the longer immersion time, and may also be facilitated by the localized adsorption and penetration of chloride ions during the prolonged immersion, which deteriorate both the microstructure and adherence of the corrosion product layer. Nevertheless, a slight reduction in anodic current density occurred between 150 and $250 \mathrm{mV}$ after the prolonged immersion, and can be related to increased thickness of the corrosion product layer.

$$
2 \mathrm{H}_{2} \mathrm{O}+\mathrm{O}_{2}+4 \mathrm{e}^{-} \rightarrow 4 \mathrm{OH}^{-}
$$


Figure 3. XPS characterization of (a) outer, (b) middle and (c) inner layer of a corrosion product formed by polarized nickel coating after $1 \mathrm{hr}$ immersion in a $3.5 \% \mathrm{NaCl}$ solution. 


\section{$X$-ray photoelectron spectroscopy (XPS)}

XPS depth profiling was employed to characterize the corrosion product layer formed by the polarized $\mathrm{Ni}$ coating after each immersion time. By sputtering at $0.04 \mathrm{~nm} / \mathrm{s}$ for 0,10 and $40 \mathrm{~s}$, a depth profiling occurred for $0,0.4$ and $1.6 \mathrm{~nm}$, and is henceforth regarded as outer, middle and inner layer, respectively. The $C 1 \mathrm{~s}$ peak remained at $284.6 \mathrm{eV}$ throughout the detections. The $N i 2 p_{3 / 2}$ peaks were detected at $852.6,853.7,856,857.7$ and $858.7 \mathrm{eV}$ binding energies. The $\mathrm{O} 1 \mathrm{~s}$ peaks were detected between $529 \mathrm{eV}$ and $533.7 \mathrm{eV}$. After $1 \mathrm{hr}$ immersion with subsequent polarization in a $3.5 \% \mathrm{NaCl}$ solution, Fig. 3(a) reveals that the surface of the Ni coating contained $\mathrm{Ni}$ species deconvoluted at $856.7 \mathrm{eV}$ (most enriched), $857.7 \mathrm{eV}$ and $858.6 \mathrm{eV}$ (least enriched), with corresponding $O 1 \mathrm{~s}$ peaks at $532.4 \mathrm{eV}$ and $533.5 \mathrm{eV}$. The binding energy at $856.7 \mathrm{eV}$ is consistent with the formation of $\mathrm{Ni}(\mathrm{OH})_{2}[11,12,19-21]$.
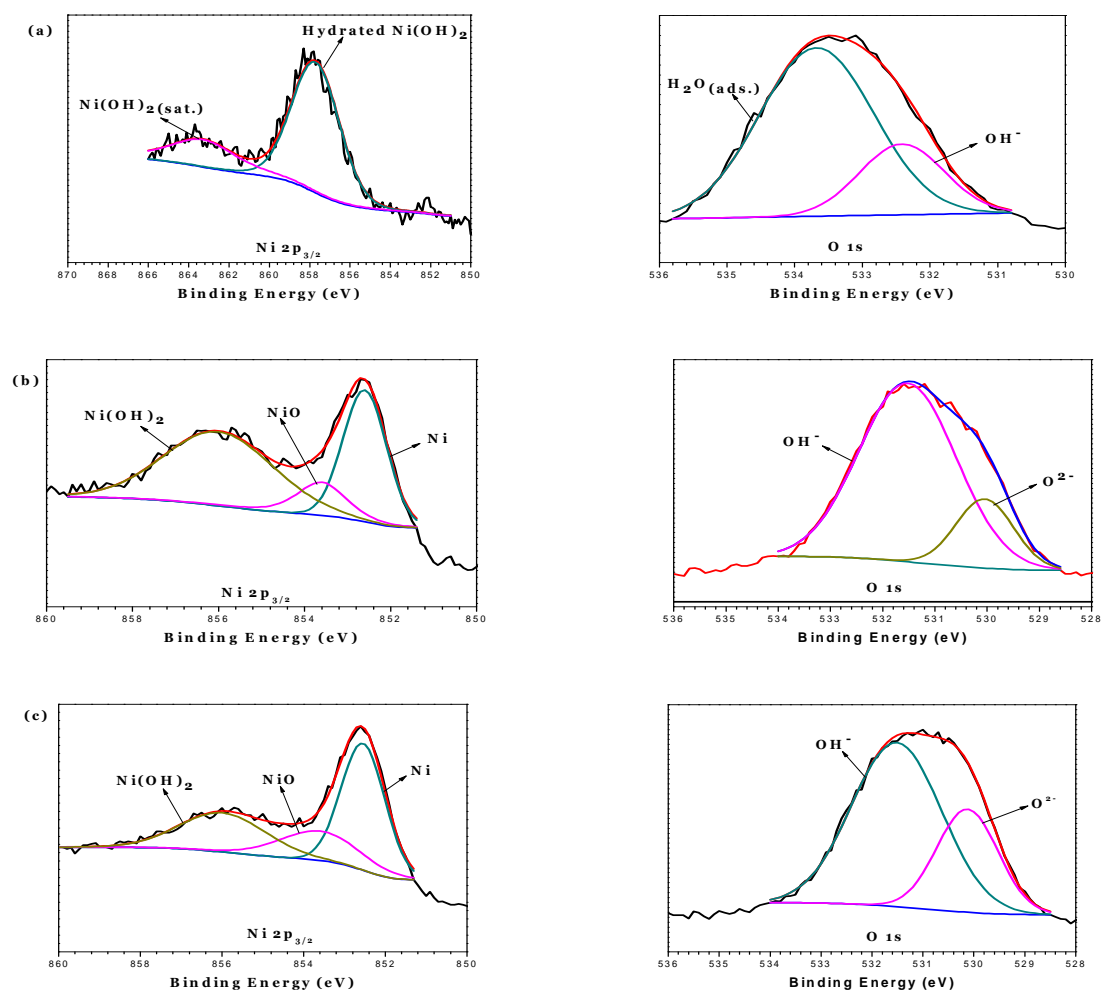

Figure 4. XPS characterization of (a) outer, (b) middle and (c) inner layer of the corrosion product formed by polarized nickel coating after $72 \mathrm{hr}$ immersion in a $3.5 \%$ $\mathrm{NaCl}$ solution.

Although higher binding energies are commonly correlated with higher oxidation state species, the phenomenon for a $\mathrm{Ni}$ oxidation to $\mathrm{Ni}^{+3}$ was not observed during the polarization experiments. The $N i 2 p_{3 / 2}$ peaks at $857.7 \mathrm{eV}$ and $858.6 \mathrm{eV}$ could, therefore, be attributed to the formation of different polymorphs of $\mathrm{Ni}(\mathrm{OH})_{2}$ with a greater degree of intercalated species like water molecules $[22,23]$. The $O 1 s$ peaks were therefore attributed to the $\mathrm{OH}^{-}(532.4 \mathrm{eV})$ and $\mathrm{H}_{2} \mathrm{O}_{\text {(ads. }}(533.5 \mathrm{eV})$. In the middle and inner layers, only $\mathrm{NiO}$ and unreacted $\mathrm{Ni}$ at $853.5 \mathrm{eV}$ and 852.6 $\mathrm{eV}[11,12]$, respectively, were detected. These peaks corresponded with $O 1 \mathrm{~s}$ 
peak at $530 \mathrm{eV}$, which confirms the formation of $\mathrm{O}^{2-}$ compounds. The peak area, hence, concentration of the $\mathrm{NiO}$ also increased with the increasing depth of the corrosion product layer. This result confirms that the corrosion resistance of the $\mathrm{Ni}$ coating in a $3.5 \% \mathrm{NaCl}$ solution is courtesy of the formation of a thin layer of $\mathrm{NiO}$ just beneath a hydroxide-enriched outer layer. Based on this configuration of an $\mathrm{O}^{2-}$-enriched layer directly beneath a $\mathrm{OH}^{-}$-enriched layer, it can also be proposed that the formation of the $\mathrm{Ni}(\mathrm{OH})_{2}$ species could be initiated by precursors like $\mathrm{NiO}-\mathrm{H}_{2} \mathrm{O}_{\text {(ads.), }}$, whereby the $\mathrm{NiO}$ particles act as nucleation sites to trigger the adsorption of $\mathrm{H}_{2} \mathrm{O}$ molecules (see Equation 2).

$$
\mathrm{Ni}+[\mathrm{O}] \rightarrow \mathrm{NiO}+\mathrm{H}_{2} \mathrm{O} \rightarrow \mathrm{NiO}-\mathrm{H}_{2} \mathrm{O}_{(\text {ads })} \rightarrow \mathrm{Ni}(\mathrm{OH})_{2}
$$

After $72 \mathrm{hr}$ immersion in a $3.5 \% \mathrm{NaCl}$ solution with subsequent polarization, only the $\mathrm{Ni} 2 p_{3 / 2}$ peak at $857.7 \mathrm{eV}$, with an associated satellite peak at $864 \mathrm{eV}$, was detected on the outer layer of the corrosion product (see Fig. 4).

The corresponding $O 1 s$ peak was observed at $533.5 \mathrm{eV}$. Compared with the characterization after $1 \mathrm{hr}$ immersion, the persistence of the peak at $857.7 \mathrm{eV}$ definitely means that the adsorption of water molecules is a characteristic of the $\mathrm{Ni}$ corrosion product layer. The peak must, therefore, be attributed to the formation of a more hydrated form of $\mathrm{Ni}(\mathrm{OH})_{2}$, such as the $\alpha-\mathrm{Ni}(\mathrm{OH})_{2}[22,23]$. The middle and inner layers contained $\mathrm{Ni}$ compounds detected at $853.6 \mathrm{eV}$ and $856 \mathrm{eV}$ which, respectively, signifies $\mathrm{NiO}$ and $\mathrm{Ni}(\mathrm{OH})_{2}$. This peak at $856 \mathrm{eV}$ must, hence, be a less hydrated $\mathrm{Ni}(\mathrm{OH})_{2}$ (such as $\beta-\mathrm{Ni}(\mathrm{OH})_{2}$ ) than the more hydrated $\alpha-\mathrm{Ni}(\mathrm{OH})_{2}$ at $857.7 \mathrm{eV}$. While the $\mathrm{NiO}$ concentration increased with a greater layer thickness, the reverse occurred for the $\mathrm{Ni}(\mathrm{OH})_{2}$ constituent. This result implies that the corrosion product layer also becomes more dehydrated with a greater layer thickness. Nevertheless, the non-dominance of the $\mathrm{NiO}$ at the corrosion product layer-substrate interface after $72 \mathrm{hr}$, compared with after 1 $\mathrm{hr}$, is the reason for the decrease in the coating corrosion resistance during immersion in a $3.5 \% \mathrm{NaCl}$ solution. Thus, the formed $\mathrm{NiO}$ must be more amorphous than crystalline, which causes it to readily be converted in the less protective $\mathrm{Ni}(\mathrm{OH})_{2}$ species, via adsorption of water molecules. The increased adsorption also implies higher incorporation and diffusion of chloride ions within the matrix of the corrosion product layer. This, subsequently, will locally deteriorate the corrosion product layer-substrate interface. SEM characterization of the pitting corrosion of such electrodeposited $\mathrm{Ni}$ coating, arising due to increased localized deterioration of the $\mathrm{Ni}$ corrosion product layer in a $3.5 \%$ $\mathrm{NaCl}$ solution, has been undertaken in an earlier report [11]. This is the reason for the increase in the corrosion rate of the Ni coating with prolonged immersion in a $3.5 \% \mathrm{NaCl}$ solution.

\section{Conclusion}

The protection characteristic of the corrosion product layer formed by an electrodeposited $\mathrm{Ni}$ coating has been investigated in a $3.5 \% \mathrm{NaCl}$ solution, using immersion time experiments. The corrosion resistance of the $\mathrm{Ni}$ coating 
decreases after $72 \mathrm{hr}$ immersion, due to the enrichment of the corrosion product layer with less protective $\mathrm{Ni}(\mathrm{OH})_{2}$ species which are readily hydrated on the surface, but dehydrated with a greater corrosion product layer thickness. The corrosion product layer also exhibited increasing porosity and weaker adhesion with the substrate, after the prolonged immersion time.

\section{Acknowledgements}

Onyeachu B. Ikenna acknowledges The World Academy of Science (TWAS) and the Chinese Academy of Science (CAS) for the award of a TWAS-CAS Postgraduate Fellowship.

\section{References}

1. Jinlong L, Tongxiang L, Wang C. J. Solid State Chem. 240(2016) 109-114.

2. Sadreddini S, Afshar A. J Appl Surf Sci. 2014;303:125-130.

3. Bakhit B, Akbari A, Nasirpouri F, et al. J Appl Surf Sci. 2014;307:351359.

4. Onyeachu BI, Oguzie EE, Njoku DI, et al. Int J Sci Technol. 2014;3:728735.

5. Peng X, Li M, Wang F. Corros Sci. 2011;53:1616-1620.

6. Qin L, Lian J, Jiang Q. Trans Nonferrous Met Soc China. 2010;20:82-89.

7. Yang X, Peng X, Xu C, et al. J Electrochem Soc. 2009;156:167-175.

8. Peng X, Zhang Y, Zhao J, et al. J Electrochim Acta. 2006;51:4922-4927.

9. Mishra R, Balasubramaniam R. Corros Sci. 2004;46:3019-3029.

10. Sziraki L, Kuzmann E, El-Sharif M, et al. J Electrochem Commun. 2000;2:619-625.

11. Onyeachu BI, Peng X, Oguzie EE, et al. Port Electrochim Acta. 2015;33:69-83.

12. Onyeachu BI, Oguzie EE, Peng X, et al. Int J Sci Technol. 2014;3:711-716.

13. Nagarajan S, Karthega M, Rajendran N. J Appl Electrochem. 2007;37:195201.

14. Ozyilmaz AT. J Surf Coat Technol. 2006;200:3918-3925.

15. Youssef KMS, Koch CC, Fedkiw PS. Corros Sci. 2004;46:51-64.

16. Seckin A, Mahir G, Serkan S, et al. J Power Source. 2016;307:796-805.

17. Zeng CL, Wang W, Wu WT. Corros Sci. 2001;43:787-801.

18. Deng Y, Yin ZM, Zhao K, et al., Corros Sci. 2012;65:288-298.

19. Machet A, Galtayries A, Zanna S. J Electrochim Acta. 2004;49:3957-3964.

20. Natarajan R, Palaniswamy N, Natesan M. Open Corros J. 2009;2:114-124

21. Grden M, Alsabet M, Jerkiewicz G. J Appl Mater Interfaces. 2012;4:30123021.

22. Grosvnor AP, Biesinger MC, Smart RC, et al. J Surf Sci. 2006;600:17711779.

23. Bode H, Del-melt K, Witte J. J Electrochim Acta. 1996;11:1079. 